\title{
Online UI/UX Platform (Crafter)
}

\section{Manasi Nikam, Ishan Gawali, Vinit Khollam, Akansksha Lokhande, Jyoti Mante}

Department of Computer Engineering, MIT polytechnic, Pune, Maharashtra, India

\begin{abstract}
Article Info

Volume 7, Issue 3

Page Number: 483-486

\section{Publication Issue :}

May-June-2021

\section{Article History}

Accepted : 25 May 2021

Published : 31 May 2021

UI/UX has evolved a lot over time and is one of the trending fields in thistech world. Companies aretrying to improve their UI UX of products to makecustomers more interact with their product A lot of designers do not get proper guidance as to which things theyshould use while practicing UI and get better results. They start taking either something beyond their capabilities or far below their skills. As a result, knowing just gives them the idea of coding but they lack in designing UI which is these days a more focused topic as clients need attractive UI where their users will get attracted towards for betterment of their product and betterment of their small or big business/company. So, for making these things simple, we're making thing web-application called CRAFTER for making all the problems solved for web-developers. Our goal is to build a strong design community for everyone out there who wants to contribute and learn UI UX designing. In the proposed system we're going to use Mean stack technology to design and for backend and Mongo DB as database. A blog system will also be designed where the UI UX designers can write their blog articles and shareit with our users. The beginner can get into our UI/UX guidelines and get started with the fundamentals of UI/UX designing. They will also have access to project starter folders which they can download and start building the product without any extra effort. The intermediate designers can refer to our component design guidelines to implement those designsand improvisethem. They can upload their UI UX workon our Behance clone platform where other users can viewappreciate and save their work.
\end{abstract}

Keywords : UI/UX, learning, designing, developing, blog, Mobile design, Typography, Web-design, Graphic design, Illustration.

\section{INTRODUCTION}

UI/UX nowadays is becoming an important aspect in our day-to-day digital life, as people want a good interface and experience in everything, good experience gives a sense of good quality and trust to the usage of the product. As we go further in this modern- day innovative tech world it is important to learn the fundamentals of user experience and interface after all user satisfaction is what matters the most at the end of the day. By considering problems faced by most people with a la ck of guide and lack of project ideas our project will help them design a good $\mathrm{UI} / \mathrm{UX}$ with proper information and assets. As they

Copyright: @ the author(s), publisher and licensee Technoscience Academy. This is an open-access article distributed under the terms of the Creative Commons Attribution Non-Commercial License, which permits unrestricted non-commercial use, distribution, and reproduction in any medium, provided the original work is properly cited 
can also add their innovative ideas while designing UI/UX. Our project will help people getting advanced with designing UI/UX, their skill set will improve. As this problem is common for all early rising birds in this field, thus we can solve this problem by making things simple and more useful to them. Also providing blog writing function for designers to share their experience with other designers.

we are going to help designers to improve their skillset by providing required assets for projectsin our web application. Implementation is done by using a Meanstack. It is an acronym for MongoDB, ExpressJS, AngularJS, and Node JS. To database from client side. When a user login's, the user can scroll through various projects in which will be displayed in card format. Users can select the project of their choice. After selecting the project user can download a folder of that project in which the user will be provided with the image of a template designed by us, also the information of Style guide for fonts, colours, optimized image assets, and HTMLfile with prewritten content. After practicing user can write a blog on experience or share some information related to UI/UX. Users can also read blogs posted by various users and increase their knowledge.

\section{Use-case diagram:}

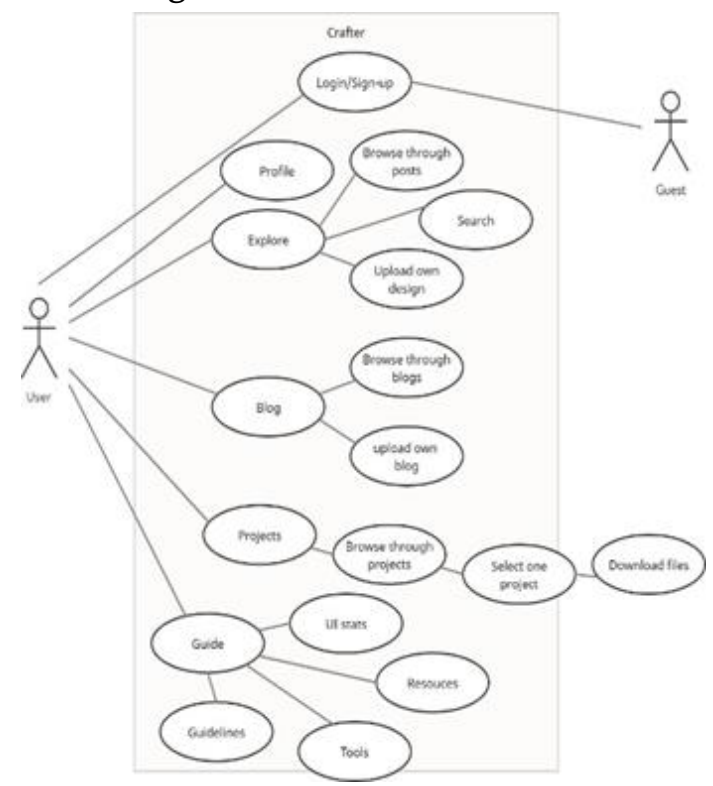

3. Moules:
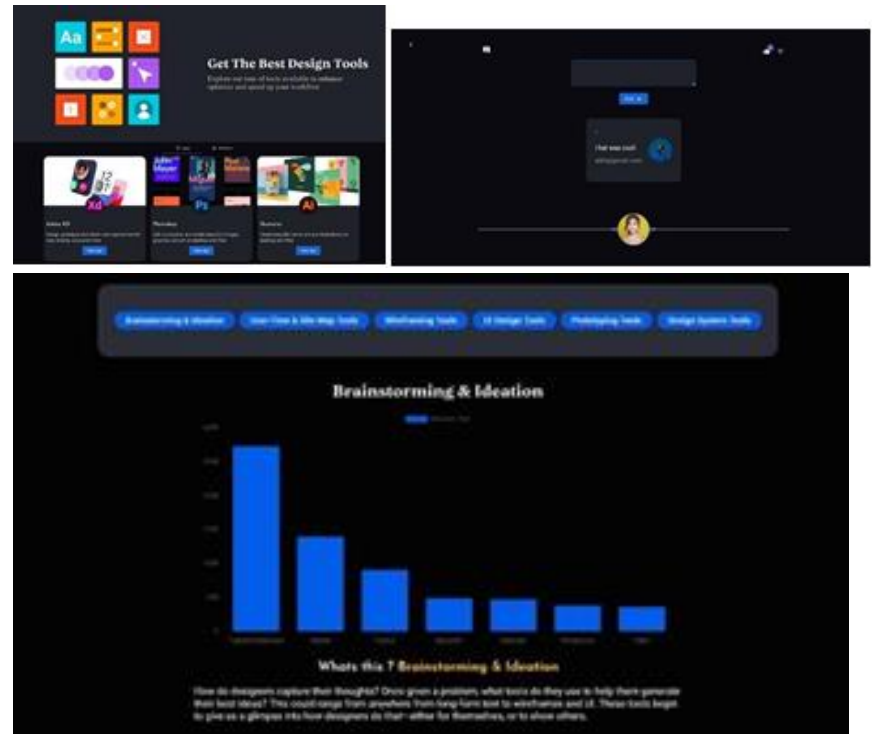

Guide:

Learning things can get difficult when you don't know what to learn? From where to learn and how to utilize resources to maximize the output. Learning UI UX design on your own without any guidance is a difficult path to follow as a beginner you are often confused which leads your morale down. our goal is to save your time surfing the web for finding resources, courses, stats, and tools. he main focus of the guide module is to give a basic understanding of UI UX designing to the user. It is further subdivided into 3 parts

- UI UX statistics - Will help users choose the best tools techniques and systems available at the moment with the help of stats.

- Tools - Will help users to know all apps and websites related to UI UX which will help designers to speed up the design process.

- Design Process - We make sure you understand the design process in the easiest way possible.

- Resources- we make sure you find the right resources for your learning curve of UI UX design. 
Explore:

When you learn a new thing, you must share your work with others and gain feedback. feedback mechanism helps you improvise your design, find faults in your design, and it is your responsibility to iterate your design and improve by taking a positive approach. In Explore module, user can explore recently uploaded designs, also can search designs according to the colour scheme he/she needs, or by tags or by type, or by typing the keywords. Users can also add a comment on one's post and can also like or dislike. User can also upload own design in the explore module by adding required information.
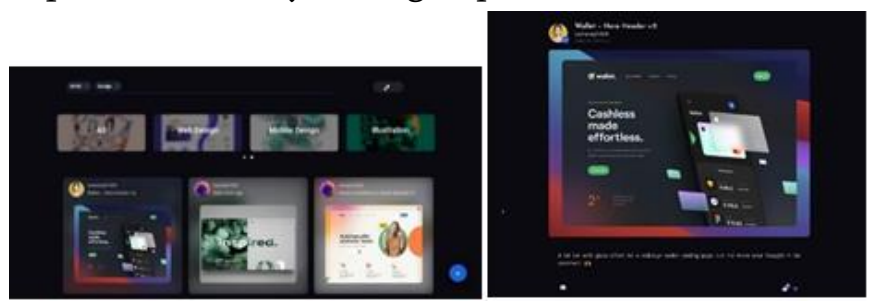

Project:

Learning concepts can never make you a successful designer, but applying those

concepts to solve real-world problems would guarantee you success. Making projects alongside learning things can always help you increase your designing skills. In this module, the user can download the sample projects according to his skill set. Users can sort the projects according to his or her needs and download the zip file which will have all the assets and style guide files. With the help of this project's users can enhance their design skills by focusing more on layout and pixel-perfect design rather than wasting time in finding images and other design resources.

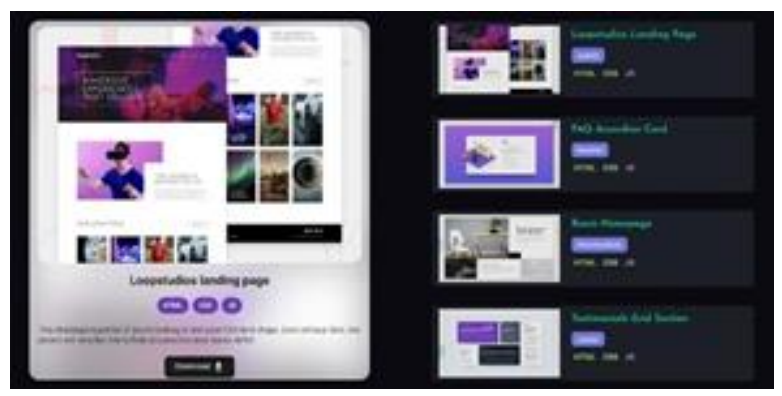

Blog:

Once you reach a certain level of excellence in any field you should always share your experience with others. sharing your experience with others will help you boost your confidence and help other people gain insights from your experience to improvise their process of doing things. In this module, users can read blogs uploaded by other users/developers. Users can also add a comment on one's blog and can also like or dislike it. Users can also search any blog there. Users can also publish his/her blog on this module. With help of this module, users can increase knowledge and also give to other developers and help them.
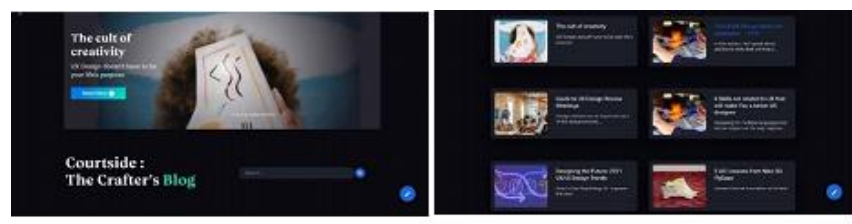

Profile:

A profile will always reflect what type of person you are and how you have evolved over the years. Make sure you maintain your profile neatly as it's a reflection of your skills mindset and dedication towards designing. This profile can help you win clients. Here we keep track of all your details and posts you have uploaded to our website. other users can view all your designs and blogs. It is like a miniportfolio that you can maintain.

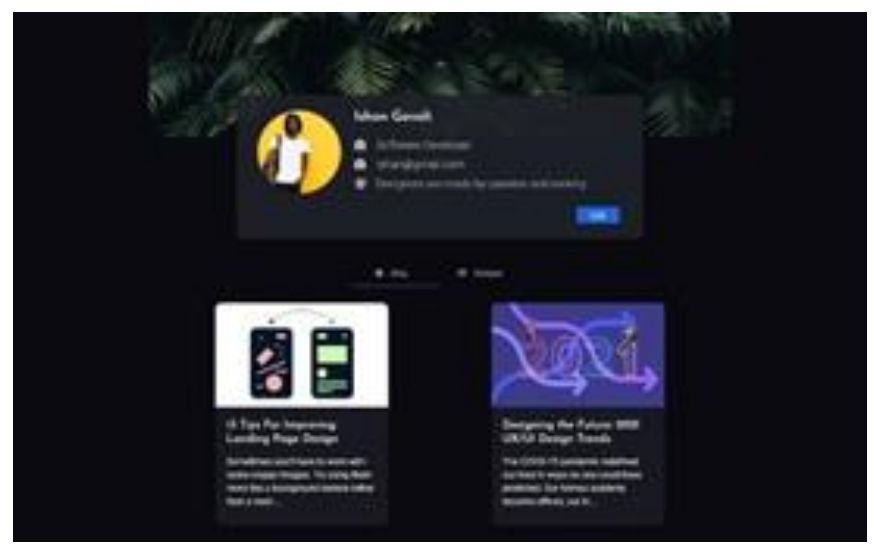




\section{CONCLUSION}

$\mathrm{UI} / \mathrm{UX}$ design is an in-demand skill in this tech world, and to survive in this outgrowing competition having technical skill is important. UI/UX is a combination of artistic abilities and technical support. Our app will help you get through the first step of this complex UI/UX learning curve. we will ensure that you will learn the things and while learning you can implement those things in the project and share your work around the globe to gain some feedback on the work. The blog writing feature will help one interact with web-developers worldwide and will also help to increase knowledge. If one thinks that the written blog has some wrong informationor doesn't like it he/she can dislike it and also write what's wrong in the blog, and also If one likes it, he/she can write in comments and also like the blog. The designs uploaded by users will help other users/designers to get an idea about the designs and will also inspire new designers. Designers can also get ideas for different color schemes and design techniques. The guide module will help new birds to know what is the current job rate foe UI/UX design over the world and can also get information related to UI/UX like what is the current demand for UI/UX around the world.

\section{REFERENCES}

[1]. Trista Liu, The Best UI/UXDesign Books \& Resources for Designers, Sep 19, 2017.

[2]. Cristian Radu, Top UI/UX articlesfor beginners, Oct 15, 2020.

[3]. Rikke Friis Dam, Teo Yu Siang, 5 stagesof design thinking process, January 2021.

[4]. Teo Yu Siang, Bad Design vs. Good Design: 5 Exampleswe learn from, August 2020.

[5]. IEEE, Usability Studies on Mobile User Interface Design Patterns: A Systematic Literature Review, 9 November 2017.
[6]. IEEE, Technology in use: The importance of good interface design, 08 February 2018.

[7]. IEEE, Using User Interface Design to Enhance Service Identification, 11 November 2008.

\section{Cite this article as :}

Manasi Nikam, Ishan Gawali, Vinit Khollam, Akansksha Lokhande, Jyoti Mante , "Online UI/UX Platform (Crafter)", International Journal of Scientific Research in Computer Science, Engineering and Information Technology (IJSRCSEIT), ISSN : 24563307, Volume 7, Issue 3, pp.483-486, May-June-2021. Available at doi : https://doi.org/10.32628/CSEIT217389 Journal URL : https://ijsrcseit.com/CSEIT217389 